\title{
Melatonin and Allergic Rhinitis
}

\author{
Aslı Çakır Çetin ${ }^{1}$, Yeşim Tunçok ${ }^{2}$, Mustafa Cenk Ecevit ${ }^{1}$ \\ 'Dokuz Eylul University Medical School, Otorhinolaryngology, İzmir, Turkey \\ ${ }^{2}$ Dokuz Eylul University Medical School, Pharmacology, İmir, Turkey \\ Address for Correspondence: Aslı Çakır Çetin, E-mail: aslicakir84@hotmail.com \\ Received: 29.10.2019; Accepted: 18.12.2019; Available Online Date: 27.01 .2020 \\ (C) Copyright 2019 by Dokuz Eylül University, Institute of Health Sciences - Available online at www.jbachs.org
}

Cite this article as: Çakır Çetin A. Tunçok Y, Ecevit MC. Melatonin and Allergic Rhinitis. J Basic Clin Health Sci 2020; 1:1-6.

\begin{abstract}
Atopy is a tendency to produce Ig-E antibodies in response to allergens and to develop allergic clinical symptoms such as allergic rhinitis, allergic bronchial asthma, and atopic dermatitis. Among them, allergic rhinitis (AR) is a chronic inflammatory disease of the intranasal mucosa, characterized by nasal symptoms reducing the quality of life. Management of AR maintains entirely symptomatic and is intended only to relieve the undesirable effects of mediators resulting from the allergic inflammatory reaction. The only disease-modifying treatment is immunotherapy, which can eliminate the pathophysiology of the disease. However, it is a long-lasting modality with several limitations and contraindications. In recent years, melatonin has been evaluated in various allergic inflammatory disorders due to its anti-inflammatory and antioxidant properties and has been suggested as a promising therapeutic. The role of melatonin has not been investigated in the treatment of $A R$, even though AR has a similar pathogenesis to those of atopic dermatitis and allergic bronchial asthma. This review is aimed to examine the pathophysiological mechanism of AR and illuminate the common pathways with atopic dermatitis and allergic bronchial asthma to discuss the potential hypothetical therapeutic role of the melatonin in AR, similar to the other two atopic diseases.
\end{abstract}

Keyword: melatonin, allergic rhinitis, atopy, asthma, atopic dermatitis, interleukin

Allergic rhinitis (AR) is a chronic disease of the upper airways, characterized by lgE-mediated inflammation of the nasal mucous membranes in the nose. Atopy and environmental factors play a role in the etiology of AR. The symptoms of AR are a runny nose, nasal congestion, sneezing, and nasal itching $(1,2)$. When exposed to the allergen, the dendritic cells (Langerhans cells), the antigen-presenting cells in the nasal mucosa, receive the allergen by endocytosis. Then the Langerhans cell proteolyzes the allergen into peptide sequences and expresses the antigen of the allergen in its surface $\mathrm{MHC}$-Class II antigen recognition site. The allergen is then transported to the regional lymph node to be introduced to naive CD4 + T lymphocytes (1). In response, Th0 cells differentiate into Th2 lymphocytes through various cytokines and transcription factors one of which is interleukin (IL)-4 released from Type 2 innate lymphoid cells. Cytokines such as IL-3, IL-4, IL-5, and granulocyte macrophage - stimulating factor (GM-CSF) are secreted from T2 lymphocytes to induce the maturation, activation, and chemotaxis of eosinophils (through IL-5); and IgE expression from B lymphocytes (through IL-4 and IL-13). Specific IgE antibodies bind to the membrane receptors of mast cells in tissues and circulating basophils. When exposed to the allergen, the allergen binds to the mast cell with its specific
IgE receptors, resulting in degranulation (1-3). Various mediators such as histamines, proteases, proteoglycans, and TNF- $\alpha$ (tumor necrosis factor-alpha) are immediately released by mast cell degranulation. The platelet-activating factor (PAF), leukotrienes (LCT4, LTD4, LTE4) and prostaglandins (PGD2) are synthesized de nova and released in minutes (4).

This process is called early phase and manifests itself in increased vascular permeability through substance $P$, neurokinin-A, vasointestinal peptide (VIP), and calcitonin gene-associated peptide (CGRP); exudation; increased nasal secretions from the submucosal glands; congestion; sneezing; and nasal itching $(1,3)$. The amount of histamine may not always correlate with findings other than sneezing, and even high levels of histamine may be present in nasal secretions of non-AR individuals. However, the number of leukotrienes and prostaglandins are often correlated with symptoms that occur in the early phase (1).

The late phase of AR usually begins within 4-6 hours after the allergen exposure, peaks after 6-12 hours and mainly characterized by the prolongation of early phase symptoms, particularly nasal congestion (1). Interleukins synthesized from mast cells (IL-4, IL-5, 
IL-6, IL-1b, and IL-13), cytokines, and chemokines such as GM-CSF and TNF- $\alpha$ are involved in this phase. These mediators contribute to eosinophilic, basophilic, and T lymphocytic infiltration of the nasal mucosa by increasing the expression of vascular adhesion molecules in endothelial cells (3).

Within four to eight hours, these inflammatory cells in the tissue begin to activate and release their inflammatory mediators. Activated epithelial cells release the thymic stromal lymphopoietin (TLSP), IL-25 and IL-33, contributing to the Th2 response, some leading to apoptosis (2). This remodeling process, which is characterized by tissue damage, inflammatory (especially eosinophilic through IL-5) cell infiltration, epithelial atrophy, goblet cell hyperplasia, and extracellular matrix thickening, is the result of the late phase of $A R(3)$.

Regulatory $\mathrm{T}$ lymphocytes (Treg) also play a role in the exacerbation of Th2 lymphocyte response, particularly through IL-10 (2). A decrease in Treg cell number and function has been demonstrated in patients with AR (5). Th17 plays a role in atopy related autoimmunity and allergic disorders, as well. A balance between Th17 and Treg cells is crucial such that excess in Th17 function and a defect in Treg function may trigger the development and progression of allergic asthma and rhinitis (6).

\section{Melatonin as a promising treatment modality}

\section{Synthesis and release of melatonin}

Melatonin (5-methoxy $\mathrm{N}$-acetyl tryptamine), released from the suprachiasmatic nucleus in the pineal gland, is a neurohormone that has been under consideration for its known effects on the circadian rhythm as well as its impact on the immune system in recent years (7). In addition to the pineal gland, many tissues are known to synthesize melatonin, such as ovarian, lens and bone marrow cells in mammals, and spleen, thymus, platelets and other immune cells in rats (8).

The precursor of melatonin is tryptophan. Tryptophan is converted to $\mathrm{N}$-acetyl serotonin by the enzyme $\mathrm{N}$-acetyltransferase and then to melatonin by the hydroxy indole-O-methyltransferase enzyme. The activity of $\mathrm{N}$-acetyltransferase is regulated periodically in a photosensitive manner. In the presence of light, the suprachiasmatic nucleus and other hypothalamic structures are stimulated, while in the dark serotonin and $\mathrm{N}$-acetyltransferase are released from the stores via noradrenaline. Between 20.00 and 23.00, the melatonin level gradually increases and peaks around 01.00-05.00. Normally, serum melatonin levels are around 0-20 picograms (pg) / milliliters ( $\mathrm{ml}$ ) in daytime and 20-200 pg / ml (average 60-70 pg / ml) at night.

\section{Pharmacokinetics of melatonin}

The hormone is highly lipophilic and partially hydrophilic. It can be administered orally by dissolving in gelatin capsules or intravenously in ethanol, and intraperitoneally. When administered intravenously, melatonin is eliminated in minutes because of its short half-time ( 0.5 to 5.6 minutes) however after oral administration it takes approximately 60 minutes to reach a peak. After oral administration, plasma distribution follows a biphasic pattern with a half-life of respectively 2 and 20 minutes and serum peak concentration is reached approximately in 60 minutes (8). The bioavailability of melatonin ranges between 10 and $56 \%$ (mean 33\%). Melatonin is metabolized rapidly and mostly in the liver and to a lesser extent in the kidney. When administered in the oral route, a ratio of $95 \%$ is exposed to a hepatic first-pass in which cytochrome P450 enzyme CYP1A2 takes a role and leads the production of a principal urinary extraction metabolite called the "6-sulfatoxymelatonin (6-SM)" (8).

Melatonin, of which synthesis is diminished by light activation, has been described in photo-immunomodulation for seasonal and intraday circadian effects on the immune system. According to data from studies on many vertebrates and humans, it is known that, as the duration of exposure to light decreases, especially during sleep and in winter, the level of melatonin increases to strengthen the immune system (7).

\section{Mechanisms of action of melatonin}

The melatonin effects in humans and other mammals by G-protein coupled membrane receptors, nuclear receptors, calmodulin and antioxidant properties (9). Melatonin G-protein coupled membrane receptors are present in the peripheral organs (spleen, thymus and all lymphocyte types, caudal artery, etc.) as well as cerebrum (cortex and suprachiasmatic nucleus) in humans $(8,10$, 11). These are the high-affinity Mel1a (ML1, ML1a, MT1, MTNR1A) mainly located in the suprachiasmatic core of the hypothalamus and low-affinity affinity Mel1b (MT2, ML1b, MTNR1B) receptors. Although post-receptor signaling mechanisms are usually carried out via the inhibition of adenylate cyclase and reduction of CAMP, Mel1b receptors also inhibit guanylate cyclase and reduce cGMP, and are known to act through different signaling mechanisms in non-human species, too $(8,10,11)$. Mel1a is mainly located in various sites of brain such as the pituitary gland, hypothalamus (suprachiasmatic nucleus), thalamus, cortex, basal ganglia, nucleus accumbens, amygdala, hippocampus, cerebellum, skin, and retina whereas Mel1b is basically seen in retina and cornea, and less frequently in cortex, hippocampus, paraventricular nucleus, and cerebellum $(8,11)$. MT3 (ML2, Quinone reductase enzyme-2 (NQO2), QR2) receptors are detoxification enzymes and located in liver, kidney, heart, lung, intestine, muscle, and brown fat tissue (11).

Melatonin might function through two types of nuclear receptors; the orphan receptor retinoid $Z$ receptor (RZR)- $\beta$ and the retinoic acid - related orphan receptor (ROR) - $\alpha, \beta$, and $\gamma(8,12)$. The nuclear receptors of melatonin are crucial for the mast cells to achieve inflammation, immune response, cell proliferation, and apoptosis mechanisms and are thought to be coupled with the transcription of NF-KB as the post-receptor signaling pathway, similar to corticosteroids (13). The transcription factor NF-kB, which is typically combined with an inhibitory molecule (I$\mathrm{kB}$ ) in the mast cell cytoplasm; is activated by phosphorylation and degradation of the I-kB when the mast cells are stimulated. During inflammation, NF-kB induces endogenous melatonin 
(MEL-n) synthesis from inflammatory cells to reguylate mast cells, by stimulating the arylalaminamine-acetyltransferase enzyme, possibly due to the presence of NF elements in the promoter and intron regions of the gene encoding this enzyme, encoding this enzyme (14). Exogenously administered melatonin does not affect the endogenous melatonin level in the presence of unstimulated mast cells. But, in the presence of stimulated mast cells, it inhibits NF-KB and reduces the endogenous melatonin level in a dose-dependent manner. This effect is assumed to suppress the exaggerated inflammatory response (13).

\section{Mechanisms of non-receptor mediated effects of melatonin}

\section{Antiapoptotic effect}

Calmodulin-mediated processing, is often associated with breast cancer. It is suggested that melatonin facilitates dephosphorylation and nuclear import of histone deacetylase 4, leading to inactivation of calmodulin-dependent protein kinase II alpha and apoptosis which may slow down the cell cycle and stop breast cancer growth. Melatonin has antiapoptotic effects in healthy cells (15).

\section{Antioxidant and cytoprotective effects}

Melatonin can easily pass through the cell membrane and reach the nucleus through its hydrophilic and lipophilic properties where it will show antioxidant and cytoprotective effects. Melatonin is a free radical scavenger and an antioxidant. It stimulates superoxide dismutase, glutathione peroxidase, and glutathione reductase enzymes. In addition to antioxidant enzyme stimulation, it also neutralizes molecules such as hydrogen peroxide, oxygen radicals, peroxynitrite anion, nitric oxide and hypochloride acid (16). Melatonin, which does not have pro-oxidative activity, is more capable than glutathione and vitanim $\mathrm{E}$ to neutralize free hydroxyl $(\mathrm{OH})$ radicals. Furthermore, unlike antioxidative substances such as vitamin $\mathrm{E}$, vitamin $\mathrm{C}$ and beta carotene, the intermediates produced during the antioxidant reactions of melatonin are also antioxidant (17). Thus, the cell membrane, nucleus, and DNA are protected from lipid peroxidation and neutralizing toxic radicals $(8,16)$. A recent experimental study demonstrated decreased apoptosis in the nasal mucosa of rhinosinusitis induced rats when treated with the melatonin (18).

\section{Immunomodulatory effects}

Melatonin receptors are also present in human lymphocytes, and human lymphocytes are shown to synthesize, secrete, and respond to melatonin $(8,12)$. Furthermore, melatonin plays a role in T cell differentiation and activation somehow (12). It promotes the production of interferon (IFN) - $\nu$ and IL-2 by both the membrane and nuclear receptors, suggesting that it may activate human Th1 lymphocytes (9). To the best of our knowledge, melatonin is an immunomodulatory hormone and influences Th1, Th2, Th17, and Treg responses, but in a varying manner. In the case of immunosuppression, melatonin inhibits the Th1, Th17, and Treg responses, while in the case of immune-exacerbation it stimulates the Treg pathways (12). Its immunomodulatory mechanism allows the production of various cytokines such as interleukin-1 (IL-1), IL-2, IL-6, IL-10; increases $\mathrm{T}$ lymphocyte activity and regulates lymphocyte proliferation; thus indirectly increases antibody production. Increased IFN- $\gamma$ and IL-2 positively feedback the synthesis of melatonin and IL-12. In addition, increased IL-2 levels lead increased Natural Killer (NK) activity (9).

Typically, CD4 + T lymphocytes are transformed into Th1 lymphocytes producing IFN- $\gamma$ and IL-2 and Th2 lymphocytes producing IL-4, IL-9, IL-10 and IL-13, which enable the maturation and activation of eosinophils. In AR, this pathway shifts to Th2 increase, Th1 decrease and IFN-y level decrease (19-21). As known, IFN- $\gamma$ is released mainly from Th1, cytotoxic $T$, naïve CD4 + T, and NK cells, and secondarily from dendritic cells, macrophages, and even $B$ lymphocytes. The promoter region of the IFN- $\gamma$ gene has a binding site of various transcription factors such as NF-KB. IFN- $\gamma$ regulates approximately five hundred genes. These include increased transcription of antigen-presenting cells genes, differentiation of naïve CD 4+ T lymphocytes towards Th 1 cell direction, increased apoptosis and $\mathrm{B}$ lymphocyte response, increased immunoglobulin heavy chain production (increased IgG and decreased IgE), and regulation of various inflammatory cells cytokines and adhesion molecules (21)

The role of melatonin in the pathogenesis of atopic diseases (Table 1)

\section{Atopic eczama and melatonin}

Atopic eczema $(\mathrm{AE})$ is dominated by aggravated Th2 response in the acute phase, which is particularly mediated by IL-4, IL-5, and IL-13, and manifests itself with a relatively decreased Th1 response and IFN- $\gamma$ levels. As the IFN- $\gamma$ increases, melatonin synthesis and serum IFN- $\gamma$ levels decrease in AE patients, and the reduced serum melatonin concentration may lead sleep disorders and stress, which results in an over-decrease in melatonin (22). The nocturnal melatonin increase was diminished in patients with atopic dermatitis compared to the control group (23), and the serum melatonin levels were significantly lower in the patients with atopic dermatitis (24). Furthermore, sleep disorders were common in patients with atopic dermatitis and found to be associated with the severity of atopic dermatitis (25). As known, the nocturnal increase of melatonin during sleep is usually associated with increased Th1 response and high serum IFN-y level (26). Since reactive oxygen species and free radicals contribute to the skin damage in $\mathrm{AE}$ (27), melatonin may be a promissing therapeutic by its antioxidative and free radical scavenger effects. The IFN- $\gamma$ to IL-4 ratio was significantly lower in the subgroup of atopic dermatitis patients with poor sleep efficiency which exhibited lower nocturnal serum melatonin levels (28).

Furthermore, atopic dermatitis-like lesions were supressed by melatonin treatment in a murine model (29). Thus, these two studies have also suggested melatonin as a treatment alternative in atopic dermatitis $(28,29)$. Another entity is called "indole-aminic theory" which has been speculated to underly the pathogenesis 
Table 1. The studies which have revealed the potential effects of melatonin in bronchial asthma, atopic dermatitis, and allergic rhinitis in historical order. Animal Studies

Martins et al., 2001 (32)

Kim et al., 2009 (29)

Shin et al., 2014 (36)

Shin et al., 2014 (38)

Wu et al., 2016 (37)

\section{Clinical Trials}

Schwarz et al., 1988 (23)

Sutherland et al., 2002 (35)

Sutherland et al., 2003 (41)

Fei et al., 2004 (33)

Dimitro et al., 2004 (26)

Chamlin et al., 2005 (25)

Muñoz-Hoyos et al., 2007 (24)

Kimata H., 2007 (22)

Gumral et al.,, 2009 (34)

Karasu-Minareci et al., 2012 (47)

Fidan et al.,2013 (44)

Shin et al., 2014 (38)

Chang et al., 2014 (28)

Wu et al., 2016 (37)

Sarnowski et al., 2016 (39)

Kleiner et al., 2016 (46)

Chang et al., 2016 (31)

Bayrak-Degirmenci et al., 2018 (6)
Airway inflammation was healed by administring exogenous melatonin in pinealectomized rats through restoring the ability of cells to migrate from the bone marrow to the bronchoalveolar fluid.

Atopic dermatitis-like dermatitis was supressed by melatonin in a murine model by reducing total IgE in serum, and IL-4 and IFN- $\gamma$ production by activated CD4+ T cells.

Melatonin-treated mice exhibited a significant reduction in

MUC5AC (a major component of the airway mucin) expression in an experimental asthma model.

Melatonin inhibited specific matrix metalloproteinases (MMP 9) induced by the production of Th 2 cells, contributing to the anti-inflammatory effect in a murine model of allergic asthma.

The expression of TLR9 (Toll like receptor 9) increased in a murine model of asthma and it corralated with the airway inflammation, and decreased serum and bronchoalveolar levels of melatonin, whereas TLR9 deficiency reversed the outcome by restoring melatonin biosynthesis.

Nocturnal melatonin increase was diminished in patients with atopic dermatitis compared to the control group. Melatonin has been shown to improve symptoms in allergic asthma by modulating the release of various inflammatory cytokines and the behavior of inflammatory cells.

In patients with nocturnal asthma, serum peak melatonin levels were significantly higher than those of the controls. In the exacerbation periods of allergic asthma, both the basal and peak melatonin levels were significantly reduced compared to the healthy control group, and the severity of symptoms was correlated with the decrease in melatonin levels. Nocturnal increase of melatonin during sleep was associated with increased Th 1 response and high serum IFN- $\gamma$ level. Sleep disorders were common in patients with atopic dermatitis and found to be associated with the severity of atopic dermatitis.

The serum melatonin levels were significantly lower in the patients with atopic dermatitis.

As the IFN- $\gamma$ increases, melatonin synthesis and serum IFN- $\gamma$ levels decrease in AE patients, and the reduced serum melatonin concentration may lead sleep disorders and stress, which results in an over-decrease in melatonin.

Serum melatonin levels and various antioxidant enzymes such as glutathione peroxidase and glutathione reductase decreased in the exacerbation period of asthma.

Melatonin strengthened contraction responses, but did not affect relaxation responses in rat tracheal smooth muscle preparations which can be considered to play a role in the pathogenesis of nocturnal asthma.

The basal and peak salivary melatonin levels of patients with allergic rhinitis were significantly lower than controls. Melatonin inhibited specific matrix metalloproteinases (MMP 9) induced by the production of Th 2 cells, contributing to the anti-inflammatory effect in a murine model of allergic asthma

The nocturnal melatonin level was found to be significantly associated with sleep disturbance in the patients with atopic dermatitis. The IFN- $\gamma$ to IL-4 ratio was significantly lower in the subgroup of patients with atopic dermaittis with poor sleep efficiency which exhibited lower nocturnal serum melatonin levels.

The expression of TLR9 (Toll like receptor 9) increased in a murine model of asthma and it corralated with the airway inflammation, and decreased serum and bronchoalveolar levels of melatonin, whereas TLR9 deficiency reversed the outcome by restoring melatonin biosynthesis.

A genetic receptor variant of melatonin (MTNR1A) was found to be associated with the paternally transmitted hereditary AR and asthma comorbidity.

Basophil deposition with increased melanocortin receptor MC1R (receptor to which melatonin-stimulating hormone binds) was observed in the nasal mucosa of both patients with allergic rhinitis and allergic rhinitis induced mice. $\alpha$-melanocyte-stimulating hormone $(\alpha-\mathrm{MSH})$ was shown to inhibit allergic airway inflammation. In children with atopic dermatitis and sleep disorder, $3 \mathrm{mg} / \mathrm{g}$ oral melatonin for four weeks has been reported to significantly reduce the severity of atopic dermatitis compared to placebo.

Lower serum IFN- $\gamma$ levels were documented in AR patients compared to controls. of $A E$, as well. Accordingly, as the serum levels of melatonin decrease somehow, various immunological defects become more prominent, and finally the organism becomes more sensitive to the environmental triggers (30). In children with atopic dermatitis and sleep disorder, $3 \mathrm{mg} / \mathrm{g}$ oral melatonin for four weeks has been reported to significantly reduce the severity of atopic dermatitis compared to placebo (31).

\section{Bronchial asthma and melatonin}

Experimental studies confirmed healing in airway inflammation by administring exogenous melatonin in pinealectomized rats
(32). In the exacerbation periods of allergic asthma, both the basal and peak melatonin levels were significantly reduced compared to the healthy control group, and the severity of symptoms was correlated with the decrease in melatonin levels (33). Besides, serum melatonin levels and various antioxidant enzymes such as glutathione peroxidase and glutathione reductase reduce in the exacerbation period of asthma (34). Melatonin has been shown to improve symptoms in allergic asthma by modulating the release of various inflammatory cytokines and the behavior of inflammatory cells (35). Antiinflammatory and antioxidant effects, as well as their effects on transcription and inhibition of mucus secretion, are among the therapeutic mechanisms of action 
found in experimental models of allergic asthma (36). Another potential therapeutic target may be the TLR9, a receptor among the toll-like receptors (TLRs) family, which is shown to have a role in the pathogenesis of bronchial asthma. Experimental studies documented that the expression of TLR9 increases in asthma and it corralated with the airway inflammation, decreased serum and bronchoalveolar levels of melatonin. On the other hand, TLR9 deficiency reversed the outcome by restoring melatonin biosynthesis (37). It is also known that melatonin inhibits specific matrix metalloproteinases (MMP 9) induced by the production of Th 2 cells, contributing to the anti-inflammatory effect in allergic asthma (38). Moreover, it has been described that genetic melatonin receptor variants can cause hereditary AR and asthma overlap (39). On the other hand, the use of melatonin is generally avoided in the patients with severe nocturnal asthma, whose serum melatonin levels are higher than the non-nocturnal matches because the nocturnal exacerbation has been speculated to depend on high melatonin levels which physiologically increases the contractility of airway smooth muscle and thus may result in bronchospasm $(40,41)$.

\section{Allergic rhinitis and melatonin}

IFN- $\gamma$ deficiency provides the basis for allergic diseases and aggravates symptoms. Similarly, the decline of Th2 cytokines to normalize IFN- $\gamma$ level is compatible with the improvement of allergies (21). IFN- $\gamma$ suppresses Th2 response while increasing Th1 response (21), reduces eotaxin receptor expression, inhibits eosinophil differentiation and regulates eosinophilic response (42). IFN- $\gamma$ also increases NO synthesis by inducing the induced nitric oxide (NO) synthase enzyme, thereby preventing Ig-E mediated degranulation of mast cells (43). Lower serum IFN- $\gamma$ levels were documented in AR patients compared to controls (6). In a study comparing salivary melatonin levels of AR patients with healthy volunteers, it was observed that both baseline and peak levels of AR were significantly lower than those of control

\section{REFERENCES}

1. Bousquet J, Vignola AM, Campbell AM, Michel FB. Pathophysiology of allergic rhinitis. Int Arch Allergy Immunol 1996;110:207-218. [CrossRef]

2. Broide DH. Allergic rhinitis: Pathophysiology. Allergy Asthma Proc 2010;31:370-374. [CrossRef]

3. Min Y-G. The Pathophysiology, Diagnosis and Treatment of Allergic Rhinitis. Allergy Asthma Immunol Res 2010;2:65-76. [CrossRef]

4. Krystel-Whittemore M, Dileepan KN, Wood JG. Mast Cell: A MultiFunctional Master Cell. Front Immunol 2016;6:620. [CrossRef]

5. Saad K, Zahran AM, Elsayh KI, Abdelmoghny A, Aboul-Khair MD. Variation of Regulatory T Lymphocytes in the Peripheral Blood of Children with Allergic Rhinitis. Arch Immunol Ther Exp (Warsz) 2018;66:307-313. [CrossRef]

6. Bayrak Degirmenci P, Aksun S, Altin Z, et al. Allergic Rhinitis and Its Relationship with IL-10, IL-17, TGF-beta, IFN-gamma, IL 22, and IL35. Dis Markers 2018;2018:9131432. [CrossRef] subjects and the circadian rhythm pattern was impaired (44). Low melatonin levels reduce IFN- $\gamma$ synthesis, which reduces melatonin synthesis $(9,28,29)$. On the other hand, IFN- $\gamma$ stimulation is known to increase melatonin synthesis (45). Basophil deposition with increased melanocortin receptor (receptor to which melatoninstimulating hormone binds) was observed in the nasal mucosa of patients with AR and mice (46).

In conclusion, atopic dermatitis and allergic asthma share a common pathophysiological process similar to AR; and that's why the melatonin, which plays an essential role in both atopic dermatitis and allergic asthma may also have a potential task in AR. To our knowledge, the only treatment modality that can modify the underlying pathogenesis of AR is subcutaneous or sublingual immunotherapy that converts the Th1 response to Th2 response (48). However, immunotherapy has several contraindications or limitations to use $(49,50)$. Nevertheless, various cytokines, receptors, and interleukins that play a role in the pathogenesis of AR have been investigated recently for potential diseasemodifying effects but have not been approved yet (50). On the other hand, the evidence-based data suggests melatonin as a very promising therapeutic agent in atopic dermatitis and allergic asthma. However, there is also insufficient data on how melatonin can be effective in AR and whether can be used for the treatment of AR. Therefore, this hypothesis should be studied either in experimental studies or in clinical trials, in all aspects.

\section{Peer-review: Externally peer-reviewed.}

Author Contributions: Concept - AÇÇ, YT, MCE; Design - AÇÇ, YT, MCE; Supervision AÇÇ, YT, MCE; Fundings - AÇÇ, YT, MCE; Materials - AÇÇ, YT, MCE; Data Collection and/ or Processing - AÇÇ, YT, MCE; Analysis and/or Interpretation - AÇÇ, YT, MCE; Literature Search - AÇÇ, YT, MCE; Writing Manuscript - AÇÇ, YT, MCE; Critical Review - AÇÇ, YT, MCE

Conflict of Interest: No conflict of interest was declared by the authors.

Financial Disclosure: The authors declared that this study has received no financial support.

7. Haldar C, Ahmad R. Photoimmunomodulation and melatonin. J Photochem Photobiol B 2010;98:107-117. [CrossRef]

8. Tordjman S, Chokron S, Delorme R, et al. Melatonin: Pharmacology, Functions and Therapeutic Benefits. Curr Neuropharmacol 2017;15:434-443. [CrossRef]

9. Garcia-Maurino S, Pozo D, Calvo JR, Guerrero JM. Correlation between nuclear melatonin receptor expression and enhanced cytokine production in human lymphocytic and monocytic cell lines. J Pineal Res 2000;29:129-137. [CrossRef]

10. Liu J, Clough SJ, Hutchinson AJ, Adamah-Biassi EB, PopovskaGorevski M, Dubocovich ML. MT1 and MT2 Melatonin Receptors: A Therapeutic Perspective. Annu Rev Pharmacol Toxicol 2016;56:361383. [CrossRef]

11. Emet M, Ozcan H, Ozel L, Yayla M, Halici Z, Hacimuftuoglu A A Review of Melatonin, Its Receptors and Drugs. Eurasian J Med 2016;48:135-141. [CrossRef]

12. Ren W, Liu G, Chen S, et al. Melatonin signaling in T cells: Functions and applications. J Pineal Res 2017;62:e12394. [CrossRef] 
13. Maldonado MD, Moreno-Garcia H, Gonzalez-Yanes C, Calvo JR. Possible Involvement of the Inhibition of NF-kbeta Factor in AntiInflammatory Actions that Melatonin Exerts on Mast Cells. J Cell Biochem 2016;117:1926-1933. [CrossRef]

14. Markus RP, Cecon E, Pires-Lapa MA. Immune-pineal axis: nuclear factor $\mathrm{kB}(\mathrm{NF}-\mathrm{kB})$ mediates the shift in the melatonin source from pinealocytes to immune competent cells. Int J Mol Sci 2013;14:1097910997. [CrossRef]

15. Hanikoglu A, Kucuksayan E, Akduman R, Ozben T. A Review on Melatonin's Effecs in Cancer: Potential Mechanisms. Anticancer Agents Med Chem 2018;18:985-992. [CrossRef]

16. Reiter RJ, Mayo JC, Tan DX, Sainz RM, Alatorre-Jimenez M, Qin L. Melatonin as an antioxidant: under promises but over delivers. J Pineal Res 2016;61:253-278. [CrossRef]

17. Pieri C, Marra M, Moroni F, Recchioni R, Marcheselli F. Melatonin: a peroxyl radical scavenger more effective than vitamin E. Life Sci 1994;55:PL271-PL276. [CrossRef]

18. Koc S, Cayli S, Aksakal C, et al. Protective effects of melatonin and selenium against apoptosis of olfactory sensory neurons: A rat model study. Am J Rhinol Allergy 2016;30:e62-e66. [CrossRef]

19. Haczku A, Macary P, Haddad EB, et al. Expression of Th-2 cytokines interleukin-4 and -5 and of Th- 1 cytokine interferon-gamma in ovalbumin-exposed sensitized Brown-Norway rats. Immunology 1996;88:247-251. [CrossRef]

20. Liao SY, Liao TN, Chiang BL, et al. Decreased production of IFN gamma and increased production of IL- 6 by cord blood mononuclear cells of newborns with a high risk of allergy. Clin Exp Allergy 1996;26:397405. [CrossRef]

21. Teixeira LK, Fonseca BP, Barboza BA, Viola JP. The role of interferongamma on immune and allergic responses. Mem Inst Oswaldo Cruz 2005;100 Suppl 1:137-144. [CrossRef]

22. Kimata $\mathrm{H}$. Elevation of salivary melatonin levels by viewing a humorous film in patients with atopic eczema. Horm Metab Res 2007;39:310-311. [CrossRef]

23. Schwarz W, Birau N, Hornstein OP, et al. Alterations of melatonin secretion in atopic eczema. Acta Derm Venereol 1988;68:224-249.

24. Munoz-Hoyos A, Espin-Quirantes C, Molina-Carballo A, et al. Neuroendocrine and circadian aspects (melatonin and betaendorphin) of atopic dermatitis in the child. Pediatr Allergy Immunol 2007;18:679-686. [CrossRef]

25. Chamlin SL, Mattson CL, Frieden IJ, et al. The price of pruritus: sleep disturbance and cosleeping in atopic dermatitis. Arch Pediatr Adolesc Med 2005;159:745-750. [CrossRef]

26. Dimitrov $\mathrm{S}$, Lange $\mathrm{T}$, Tieken $\mathrm{S}$, Fehm HL, Born J. Sleep associated regulation of $T$ helper $1 / T$ helper 2 cytokine balance in humans. Brain Behav Immun 2004;18:341-348. [CrossRef]

27. Sivaranjani N, Rao SV, Rajeev G. Role of reactive oxygen species and antioxidants in atopic dermatitis. J Clin Diagn Res 2013;7:2683-2685. [CrossRef]

28. Chang YS, Chou YT, Lee JH, et al. Atopic dermatitis, melatonin, and sleep disturbance. Pediatrics 2014;134:e397-405. [CrossRef]

29. Kim TH, Jung JA, Kim GD, et al. Melatonin inhibits the development of 2,4-dinitrofluorobenzene-induced atopic dermatitis-like skin lesions in NC/Nga mice. J Pineal Res 2009;47:324-329. [CrossRef]

30. Marseglia L, D’Angelo G, Manti S, et al. Melatonin and Atopy: Role in Atopic Dermatitis and Asthma. Int J Mol Sci 2014;15:13482-13493. [CrossRef]

31. Chang YS, Lin $M H$, Lee $J H$, et al. Melatonin Supplementation for Children With Atopic Dermatitis and Sleep Disturbance: A Randomized Clinical Trial.JAMA Pediatrics 2016;170:35-42. [CrossRef]

32. Martins E Jr, Ligeiro de Oliveira AP, Fialho de Araujo AM, Tavares de Lima W, Cipolla-Neto J, Costa Rosa LF. Melatonin modulates allergic lung inflammation. J Pineal Res 2001;31:363-369. [CrossRef]
33. Fei GH, Liu RY, Zhang ZH, Zhou JN. Alterations in circadian rhythms of melatonin and cortisol in patients with bronchial asthma. Acta Pharmacol Sin 2004;25:651-656. http://www.chinaphar.com/article/ view/8196/8800

34. Gumral N, Naziroglu M, Ongel K, et al. Antioxidant enzymes and melatonin levels in patients with bronchial asthma and chronic obstructive pulmonary disease during stable and exacerbation periods. Cell Biochem Funct 2009;27:276-283. [CrossRef]

35. Sutherland ER, Martin RJ, Ellison MC, Kraft M. Immunomodulatory effects of melatonin in asthma. Am J Respir Crit Care Med 2002;166:1055-1061. [CrossRef]

36. Shin IS, Park JW, Shin NR, et al. Melatonin inhibits MUC5AC production via suppression of MAPK signaling in human airway epithelial cells. J Pineal Res 2014;56:398-407. [CrossRef]

37. Wu HM, Shen QY, Fang L, et al. JNK-TLR9 signal pathway mediates allergic airway inflammation through suppressing melatonin biosynthesis. J Pineal Res 2016;60:415-423. [CrossRef]

38. Shin IS, ParkJW, Shin NR, et al. Melatonin reduces airway inflammation in ovalbumin-induced asthma. Immunobiology 2014;219:901-908. [CrossRef]

39. Sarnowski C, Laprise C, Malerba G, et al. DNA methylation within melatonin receptor 1A (MTNR1A) mediates paternally transmitted genetic variant effect on asthma plus rhinitis. J Allergy Clin Immunol 2016;138:748-753. [CrossRef]

40. Weekley LB. Influence of melatonin on bovine pulmonary vascular and bronchial airway smooth muscle tone. Clin Auton Res 1995;5:5356. [CrossRef]

41. Sutherland ER, Ellison MC, Kraft M, Martin RJ. Elevated serum melatonin is associated with the nocturnal worsening of asthma. J Allergy Clin Immunol 2003;112:513-517. [CrossRef]

42. Fulkerson PC, Zimmermann N, Brandt EB, et al. Negative regulation of eosinophil recruitment to the lung by the chemokine monokine induced by IFN-gamma (Mig, CXCL9). Proc Natl Acad Sci U S A 2004;101:1987-1992. [CrossRef]

43. Eastmond NC, Banks EM, Coleman JW. Nitric oxide inhibits IgE-mediated degranulation of mast cells and is the principal intermediate in IFN-gamma-induced suppression of exocytosis. J Immunol 1997;159:1444-1450. https://www.jimmunol.org/ content/159/3/1444.long

44. Fidan V, Alp HH, Gozeler M, Karaaslan O, Binay O, Cingi C. Variance of melatonin and cortisol rhythm in patients with allergic rhinitis. Am J Otolaryngol 2013;34:416-419. [CrossRef]

45. Finocchiaro LM, Nahmod V, Launay J. Melatonin biosynthesis and metabolism in peripheral blood mononuclear leucocytes. Biochem J 1991;280:727-231. [CrossRef]

46. Kleiner S, Braunstahl GJ, Rudrich $U$, et al. Regulation of melanocortin 1 receptor in allergic rhinitis in vitro and in vivo. Clin Exp Allergy 2016;46:1066-1074. [CrossRef]

47. Karasu-Minareci E, Kaya $Y$, Belgin Yildirim F. The achilles heel in melatonin: asthma. Iran J Allergy Asthma Immunol 2012;11:246-252. [CrossRef]

48. Ricketti PA, Alandijani S, Lin CH, Casale TB. Investigational new drugs for allergic rhinitis. Expert Opin Investig Drugs 2017;26:279-292. [CrossRef]

49. Durham SR, Creticos PS, Nelson HS, et al. Treatment effect of sublingual immunotherapy tablets and pharmacotherapies for seasonal and perennial allergic rhinitis:Pooled analyses. J Allergy Clin Immunol 2016;138:1081-1088.e4. [CrossRef]

50. Castillo J, Dimov V. Investigational drugs for the treatment of allergic rhinitis. Expert Opin Investig Drugs 2014;23:823-836. [CrossRef] 